\section{Road stormwater basins as accumulators lead the way to the study of the traffic-induced antimony contamination}

\author{
MAËVA PHILIPPE ${ }^{1,2}$, PIERRE LE PAPE ${ }^{3}$, LOUISE
} BORDIER $^{4}$, LUDOVIC DELBES ${ }^{3}$ AND MRS. SOPHIE AYRAULT $^{5}$

${ }^{1}$ LSCE (CEA-CNRS-UVSQ, Univ Paris Saclay) \& IMPMC (CNRS, Univ Sorbonne, MNHN, IRD)

${ }^{2}$ LSCE (CEA-CNRS-UVSQ)

${ }^{3}$ IMPMC (CNRS-IRD-MNHN)

${ }^{4}$ LSCE/IPSL, CEA-CNRS-UVSQ

${ }^{5}$ LSCE (CEA-CNRS-UVSQ), Univ Paris Saclay

Presenting Author: maeva.philippe@1sce.ipsl.fr

Urban surfaces represented $0.5 \%$ of the surface of the globe in 2000 with $300000 \mathrm{~km}^{2}$ and are expected to quadruple by 2050[1]. With urbanization come social, health and environmental challenges such as traffic pollution, raising important health and environmental concerns. Technological changes coupled with environmental regulations have changed the nature and impact of traffic emissions overtime. Antimony $(\mathrm{Sb})$, now used in brake pad alloys with copper $(\mathrm{Cu})$, cadmium (Cd) and zinc ( $\mathrm{Zn})$ to replace asbestos after its ban in numerous countries in the late 90's has become an emerging contaminant in urban environments. To better understand traffic impacts on its surrounding environments, it is necessary to determine the pathways of these contaminations. Stormwater basins stand as models of accumulation media, and are thus interesting to study traffic contamination.

We collected 43 sediments, 3 road dust sediments, 13 dissolved and suspended maters fractions and 8 plant samples in highway stormwater ponds presenting different characteristics (urban/rural, 10 to 30 years old). Combining mineralogical, elemental and radiogenic lead isotopes ratio approaches, we aimed at better defining the legacy and emerging traffic related inorganic contaminants. Our results show that samples are highly enriched in $\mathrm{Sb}, \mathrm{Zn}, \mathrm{Cu}$ and $\mathrm{Cd}$ with enrichment factors (enrichment compared to the local geochemical background) median of 20 for $\mathrm{Sb}$ and 6 for $\mathrm{Zn}, \mathrm{Cu}$ and $\mathrm{Cd}$ (Fig. 1). Pond samples mineralogy not only reflects geogenic components but also specific inputs of traffic-related minerals such as asbestos. Additionally, metal-containing particles like Fe and Mn oxides carrying $\mathrm{Cu}, \mathrm{Cr}$ or $\mathrm{Zn}$ have been identified. Lead isotopes ratio measured in the solid fractions reveals the remanence of lead gasoline in $\sim 30$ years old stormwater ponds, not detected in our recent basins, and a variability between sediment and suspended particulate fractions signatures, pointing to differential transport modes. Results validate the use of stormwater basins as accumulation environments for traffic-related contaminants. In particular, our work highlights the potential of the use of $\mathrm{Sb}$ as a new tracer to decipher the contribution of traffic-related emission to the urban contamination while $\mathrm{Pb}$ may no longer be relevant.

[1] Angel et al. (2011) Prog. Plan. 75(2), 53-107 